\title{
Characteristics of Environmental Conflicts Caused by Illegal Gold Mining in West Kalimantan, Indonesia
}

\author{
Nafsiatun $^{1}$, Priyo Saptomo ${ }^{2}$, Warsun Najib ${ }^{3}$, Hartini ${ }^{4}$ \\ ${ }^{1,2}$ (Faculty of Law, Tanjungpura University, Indonesia) \\ ${ }^{3}$ (Faculty of Engineering, Gadjah Mada University, Indonesia) \\ ${ }^{4}$ (Faculty of Law, Gadjah Mada University, Indonesia)
}

\begin{abstract}
Illegal gold mining in West Kalimantan, Indonesia has lasted so long. Based on the survey of the Ministry of Energy and Mineral Resources of the Republic of Indonesia shows that illegal gold mining area in West Kalimantan spread accros 6 districts, with a mine about 200 point. Illegal gold mining has resulted in damage to the environment of concern. These conditions resulted in vertical and horizontal conflicts that affect people's lives the illegal gold mining area. This study aimed to investigate the characteristics of environmental conflicts arising from the illegal gold mining. Research conducted observation is accompanied by an interview in the conflict area. The sample districts selected 3 districts with the highest conflict locations so as to know the character of the conflict in the area.
\end{abstract}

Keywords: Illegal gold mining, environmental conflicts, West Kalimantan, Indonesia

\section{INTRODUCTION}

Management and utilization of natural resources is a strategic field because it involves the welfare of Indonesian society. Development to manage and utilize the environment, in addition to improving the welfare of people also contain potential as the source of conflict between communities, society and government/local government and the community with employers [1]. It is not independent of the inverse relationship between the growth of the user or the user's environment with environmental constraints in reforming itself to meet human needs. The condition is worse than the management of natural resources is illegal mining. It is further worsen the environmental damage due to development without sustainable concepts and planning. One is illegal gold mining in West Kalimantan, Indonesia. Illegal gold mining has lasted long time in West Kalimantan eventually cause pollution and environmental damage. Environmental degradation is a problem because of prolonged damage the ecosystem and neither party was responsible for the damage and recovery. The difference of views on the handling of illegal gold mining implications for the resulting complexity of the problems such as: (1) the former lands destroyed illegal gold mining without remediation (2) expanding new areas illegal gold mining penetrated the forest and productive land (3) disruption of the water supply (4) the effect of mercury has been showed disruption of public health (5) increasing poverty because marginalited local residents by newcomers who seek to profit from illegal gold mining. These problems eventually led to a prolonged conflict in the mining area that requires all stakeholders ie community, government and business to work together to resolve conflicts related to the environment in mining areas through good policies and programs. So this research infrastructures to knowing the exact pattern of conflict resolution and how to empower the community towards improving the welfare of considering mining should be used for public welfare.

\section{REVIEW OF THE LITERATURE}

Mining and energy sector is an important development for Indonesia. The mining industry as a concrete form of the mining sector accounted for about $11.2 \%$ of the value of Indonesia's exports and contributes about $2.8 \%$ of the gross domestic product (GDP). The mining industry employs about 37.787 people workforce Indonesia, an amount not less. But in terms of the environment, is considered the most destructive mining activities than other natural resource exploitation. Mining can change the shape of the landscape, damage and or eliminate vegetation, resulting in tailings, or waste rock, and drain ground water and surface water. If not rehabilitated, ex-mining lands will form a giant puddle and barren stretch of land that is acidic [2].One important issue in the development of mining versus environmental sustainability are overlapping and land use conflicts, especially with forestry. On the one hand, mining is the mainstay of foreign exchange earnings, as well as 'the driving force' growth in Eastern Indonesia. On the other hand, the forestry sector also plays an important role in the national economy. Overlap between the two potential conflict of interest. To bridge this purpose, precise and comprehensive policy is needed that is able to optimize the development of the forestry sector, and mining, as well as "friendly" to the environment. This policy will also be expected to provide consistency, clarity, and coordination from the government to the mining entrepreneur in business. Moreover, the illegal miners are very environmentally damaging and irresponsible. The need for appropriate 
Characteristics of Environmental Conflicts Caused by Illegal Gold Mining in West Kalimantan,

rules and sanctions for illegal mining by law to deliver justice. Historically illegal gold mining perpetrators in West Kalimantan begins with the District Singkawang then expand to other regions and is currently based in Bengkayang and Kapuas Hulu. Sharing system among investors (financiers) and the public at 70:30. This can greatly affect the locals who came from an agrarian society.

Mining activities have been the source of various conflicts caused by policy and regulatory uncertainties over land use and property rights, illegal artisanal mining (artisanal mining is often, but not always, small scale; it can also refer to larger and somewhat coordinated mining operation that are not assosiated with legal mining companies), pollution and environmental impacts and uncertainty surrounding the livelihoods of local resident after mining closure. These conflicts are being exposed and have become more pronounced under the current structure of decentralization of authority to local governments and a substantially freer social and political environment [3].

The industrial sector in addition to increasing and advancing the standard of people's lives, it is also a negative impact to people's lives. The impact occurred as a result of industrial operations that ignore the existing norms. Inflicted fatal damage to the environment are disrupting the lives of the community itself [4]. Therefore, the management of natural resources need to be re-examined by reviewing the management of natural resources. The mandate of rearranging the natural resource management can be reviewed in five aspects, namely the mandate philosophical, sociological, ecological, political and juridical [5].

Appropriate policies and synergy with various parties need to West Kalimantan local government to resolve environmental conflicts in the various districts. The parties concerned in the management and utilization of natural resources of gold in West Kalimantan have two-way communication that takes place justice. Communication is necessary to know the desires and interests are expected to be placed within the framework of equitable and sustainable development. Various conflicts is basically a tripartite interests of communication is not smooth because of the imbalance of power. To achieve the synergistic conditions tripartite relationship between government, employers and the public to walk in balance. The balance will occur when communication goes in the right order and proportional [6],[7]. The need for information and communication center that provides the accuracy and correctness of information about the environment.

Deteriorating environmental conditions in Indonesia from year to year continues to grow. The number of disputes due to damage or loss of quality growing environment. This indication is evident from the number of complaints received by the Ministry of Environment during the years 2002-2006 [8].

\section{METHODOLOGY}

The study was conducted with a community approach through directly involved in the mining area to explore information in order to obtain timely and accurate data to identify and characterize environmental conflicts that occur in accordance with the data obtained in the preliminary survey on some of the mining areas.This exploratory approach will pay attention to socio-cultural community so communication will go smoothly and provide appropriate feedback and objective. Approach to the regulator is also a continuous interrelated agencies so that information goes balanced. Object of research is the area of mining communities both local and migrant communities, local governments each mining area and mining entrepreneur. The selection of objects is done by sampling method in accordance with the parameters of the study are expected. Researchers conducted interviews with study objects with two-way communication in a balanced and objective tenatang aspects of research. Provide sheet of questions to determine the characteristics of the object of research related to environmental conflicts. This interview was conducted as part of the documentation of data sources in this study.

This research is based on observation and interview for four month (June-September 2012) in three districts (Sintang, Sanggau and Ketapang in West Kalimantan, Indonesia). The choice of these districts based on information from local government and preliminary research.

\section{RESULTS AND DISCUSSION}

The study was conducted in 3 districts (Sintang, Sanggau and Ketapang) with the location of illegal gold mining has caused many conflicts and the environment because of pollution it generates. People in the three districts has been observation and interviews with some of the questions about environmental pollution and the resulting conflicts. Based on the data obtained it is known that the condition of illegal gold mining area suffered severe damage to the environment, public health problems, especially skin diseases and suspected genetic abnormalities in multiple births. This condition has lasted a long time and several complaints have been submitted to the local government. But due to lack of coordination so that the problem was never fully resolved. This led to a prolonged conflict and unprecedented settlement obvious solution. Conflicts in 3 districts that have used samples showed that (1) environmental conflicts caused by illegal gold mining is incidental and chronic (this happens because no deep understanding of the environment and the integrality between actors actors illegal gold mining) (2) conflict localization means that only at certain locations with the same conflicts but not when seen from the same material conflict exists so this reinforces the notion that the conflict is only a short-term 
Characteristics of Environmental Conflicts Caused by Illegal Gold Mining in West Kalimantan,

interests (3) the absence of integrative handling of policy makers so that the conflict -conflict environment can be expected to continue to take a long time if there is no solution integrality. Conflicts also showed a characteristic that is influenced by culture, education and local government leadership. In illegal gold mining sites in 3 districts sampling distinguished on the river and the area of land is not productive or unproductive. At the district Ketapang illegal gold mining sites are most streams while the district Sanggau and Sintang be productive or unproductive land, including forests. Illegal gold mining in watershed health cause more conflict because people use the river water for their daily needs, while the conflict in productive or unproductive land are more common as they relate to land ownership and land degradation. The influence of culture and education level is evident in the intensity of the conflict. In the area of illegal gold mining sites in the land productive or non-productive conflict occurs more frequently than in the watershed and the solution difficult. Local government leadership also affects conflict. Some local leaders are persuasive approach, but some are not powerless against the prolonged conflict.

\section{CONCLUSION}

Based on environmental conflict that occurred in 3 districts, we can conclude that the characteristics of the conflict is influenced by culture, education level, geographic and local government leadership style

\section{Acknowledgements}

We are grateful to the Directorate of Higher Education, Ministry Education, Republic of Indonesia for foundation this research

\section{REFERENCES}

[1] Suhardjana, J., Managing conflict environment in order to achieve a suistainable regional development, Sustainable Earth Journal, 9 (2), 2009, 300-3005

[2] Lubis, R., Impact of the economic crisis on the environment : overview of the strategic environmental assessment (environmental strategic assesman) (Jakarta, Directorate Mineral Resources and Mining, Republic of Indonesia, 2006)

[3] Resosudarmo, B.P., Resosudarmo, I.A.P., Sarosa, W., and Subiman, Sosioeconomic conflicts in Indonesia's mining industry, in Cronin, R., and Pandya Amit (Ed.), Exploiting natural resources, (Washington DC : The Henry L. Stimson Center, 2009) 34-46

[4] Waluyo, Identification of causes and environmental dispute settlement pattern in district Karanganyar, Yustisia of Journal, 69, 2006, 44-52

[5] Chandradewi, R. and Pratiwi, W., Agenda setting repeat natural resource management, Legal Advocacy and Policy Bulletin Natural Resource Management, 2 (2), 2003, 3-6

[6] Zulkarnain, I., Pudjiastuti, T.N., and Karomah U., Potential conflicts in mining areas: the case Pongkor and Cikotok, (Jakarta, LIPI: 2003)

[7] Lelo, F., Chiuri, W., and Jenkins, Managing the river Njoro watershed, Kenya : conflicting laws, policies and community priorities, Proc. International Workshop on Africa Water Laws, Johannesburg, 2005

[8] Sadiawati, D, The effectiveness of environmental dispute resolution in Indonesia, policy recommendations, (Jakarta, Bappenas : 2011) 